九州大学学術情報リポジトリ

Kyushu University Institutional Repository

Fungus Gnats of the Genus Neuratelia Rondani in Japan (Diptera : Mycetophilidae)

Sasakawa, Mitsuhiro

https://doi.org/10.5109/2683

出版情報 : ESAKIA. 44，pp.67-79，2004-03-31. Entomological Laboratory，Faculty of Agriculture， Kyushu University

バージョン:

権利関係 : 


\title{
Fungus Gnats of the Genus Neuratelia Rondani in Japan (Diptera: Mycetophilidae)
}

\author{
Mitsuhiro SASAKAWA \\ 7-6-7 Korigaoka, Hirakata City, Osaka Pref., 573-0084 Japan
}

\begin{abstract}
Five new species of the genus Neuratelia (Mycetophilidae) are described from Japan: japonica, yukawai, tibialis, microdigitata and kamijoi. They are closely related to each other in general appearance, but they have the specific pregenital tergites and sternite, and male genitalia, respectively, as figured. A key is provided to the seven species from Japan.
\end{abstract}

Key words: taxonomy, Mycetophilidae, Neuratelia, new species.

\section{Introduction}

The genus Neuratelia Rondani, 1856, belongs to the tribe Sciophilini of the subfamily Sciophilinae, and is represented by six species in the Palaearctic region (Matile, 1974, 1988). It is characteristic in the wing venation, such as the disappearance of basal part of $\mathbf{M}_{1}$, and distinct curvature of $R_{5}$ as well as in the genus Anaclileia Meunier, 1904.

Two species, Neuratelia femorata Okada, 1937, and N. nemoralis (Meigen, 1818), are known to occur in Japan (Okada, 1939; Sasakawa, 1965; Kimura, 1976). In this paper, five new species collected by sweeping in Japan are described.

\section{Materials and methods}

Materials are dried specimens. The male genitalia were macerated with $30 \% \mathrm{KOH}$ and transferred to distilled water for dissection, and the abdomen (sometimes the distal segments only) and genitalia were preserved in a polyethylene tubule ( $2 \mathrm{~mm}$ in diameter, about $15 \mathrm{~mm}$ in length) with glycerol. Abbreviations for the tibial short bristles are as follows: ad- anterodorsal bristles, d- dorsal, pd- posterodorsal.

The holotypes and paratypes of the new species are deposited in the collections of the Osaka Museum of Natural History (OMNH, Nagai Park, Osaka) and the Laboratory of 
Systematic Entomology, Hokkaidô University (HU, Sapporo), respectively.

\section{Genus Neuratelia Rondani}

Neuratelia Rondani 1856, Dipt. Ital. Prodromus, 1: 195. Type-species, Mycetophila nemoralis Meigen, 1818, by original designation.

Neuratelia is a small genus belonging to the subfamily Sciophilinae of the family Mycetophilidae. It is characterized by the wing venation, that is, costa extending slightly beyond tip of vein $\mathrm{R}_{5}$, subcosta ending in costa beyond the level of forking point of $\mathrm{CuA}$, crossvein sc-r situated before middle of subcosta, $\mathrm{R}_{5}$ strongly curved forwardly, crossvein $r-m$ almost as long as Rs, basal part of $M_{1}$ disappeared, and by the presence of long setae on the mediotergite and laterotergite, and the upwardly directed genitalia.

Two species have been recorded from Japan but five new others having the specific male genitalia can now be added. In a general way, coloration of their thorax and abdomen is divided into two forms: pale (testaceous to brown) and dark (brownish black to black), but those are rarely variable within the species. The present study of male Neuratelia has suggested further specific character state in the shape of pregenital tergites (T8-9) and sternite (S8) in addition to the highly specific genital characters. These are employed in the key and figured for the species. Namely, the tergites are either emarginated at middle of anterior margin or projected at middle of posterior margin and the sternite is distinctly enlarged in a form of pentagon in contrast with the normal trapezoid of the tergite or sternite, and may be apomorphic.

\section{Key to Japanese species of Neuratelia (male)}

1. Mesoscutum testaceous to brown............................................. 2

- Mesoscutum brownish black to black........................................... 4

2. T8 with mediocaudal projection; T9 trapezoid, with posterior margin straight or weakly emarginated; ventral stylomere of gonostylus present or absent; mid tibia of normal thickness ............................................................ 3

- T8 almost trapezoid; T9 narrowed posteriorly and hollowed at end; ventral stylomere bidentate before apex; mid tibia swollen on basal half..................tibialis $\mathrm{n}$. $\mathrm{sp}$.

3. Dorsal stylomere projected inward, without teeth; ventral stylomere small, with three short spines on tip. japonica n. sp.

- Dorsal stylomere with a strong tooth; ventral stylomere absent but posteroventral prolongation of gonocoxite with about ten spine-like setae on tip.......yukawai n. sp. 
4. Fore femur without distinct bristles ventrally................................ 5

- Fore femur with two dense ventral rows of pale brown bristles.......femorata Okada

5. Abdominal tergites blackish brown; palpus entirely yellow; T8-9 each with deep excavation on anterior margin; gonocoxite with posterodorsal processes in addition to ventrolateral prolongation; mesal stylomere absent......................... 6

- Abdominal tergites with yellow posterior markings; palpus with fourth palpomere brown; T8-9 each with shallow emargination on anterior margin; gonocoxite without dorsal processes but with narrow processes on ventrolateral side; mesal stylomere well-developed, with about eight-fingered lobe. microdigitata $\mathrm{n}$. sp.

6. Gonocoxite with posterodorsal process weakly pointed on tip; paramere with long incurved apex..........................................nemoralis (Meigen)

- Gonocoxal posterodorsal process pointed on tip and with two teeth before apex; paramere with shortly angulated apex kamijoi $\mathrm{n}$. sp.

\section{Neuratelia japonica sp. nov.}

(Fig. 1)

Malle.

Head brown but face and clypeus yellow to testaceous. Antenna with scape and pedicel yellow, flagellomeres pale brown but first flagellomere yellow, second to third (or fourth) flagellomeres yellowish basally; palpus yellow. Thorax shiny testaceous; scutum except for pale anterolateral part and scutellum brown. Wing hyaline, very faintly tinged with brownish yellow; halter yellow, with knob sometimes brown-tinged at base. Legs yellow; coxae more or less testaceous, tarsi faintly brown-tinged. Abdomen with tergites shiny brown and sternites testaceous yellow. Setae and setulae yellowish brown to pale brown.

Ocelli situated almost on a same transverse line; face and clypeus densely setose. Antenna extending just beyond posterior margin of scutellum or to posterior margin of $\mathrm{T} 1$; scape and pedicel each setose marginally; flagellomers covered with whitish hairs; flagellomeres in relative length of 4.7-5(first) : 2.9-3(second to fifth) : 3.1-3.2(sixth to thirteenth) : 3.4-3.6(fourteenth); fourth flagellomere twice as long as broad, thirteenth flagellomere thrice as long as broad. Palpus with four palpomeres in relative length of $2: 2.5: 5.6: 8$, first and second palpomeres setose distally, third and fourth ones setose sparsely throughout whole surface.

Scutellum with three to four long apical setae; mediotergite with long setae on posterior and posterolateral parts; laterotergite with long setae throughout whole surface. Wing covered densely with brownish macrotrichiae; costa ending at or a little beyond tip of $\mathrm{R}_{5}$; Sc ending in $\mathrm{C}$ at middle of distance between $\mathrm{h}$ and tip of $\mathrm{R}_{1}$; crossvein sc-r 

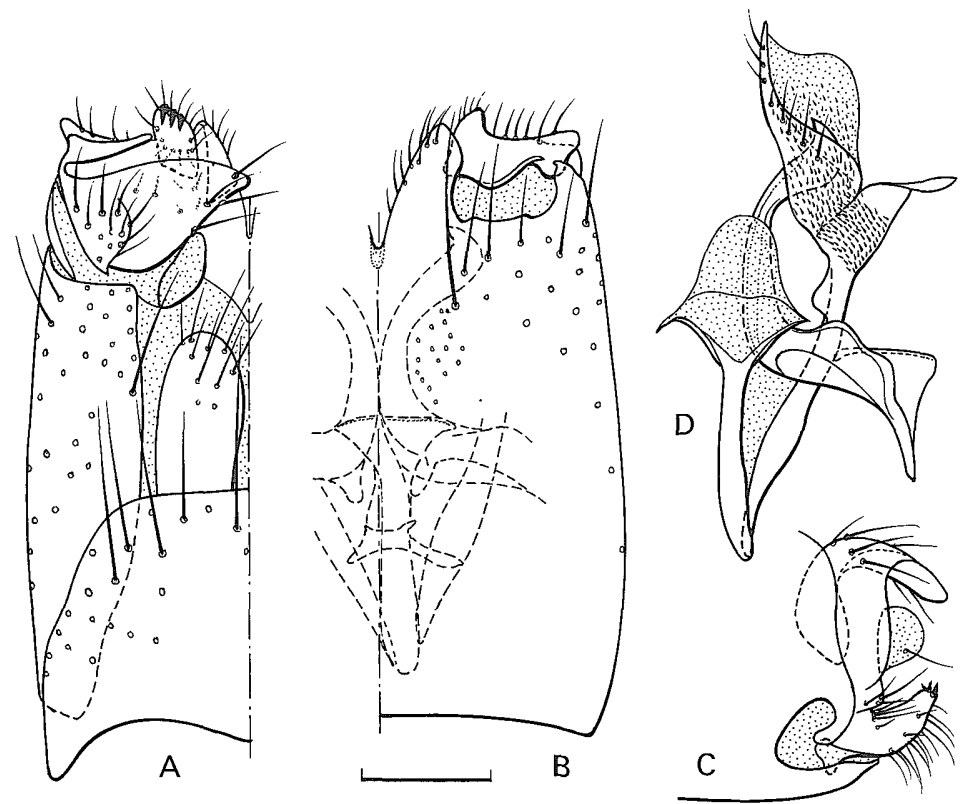

Fig. 1. Male genitalia of Neuratelia japonica sp. nov. (paratype, Koza). A, ninth tergite, cercus, gonocoxite and gonostyli, right half, dorsal view; B, gonocoxite and ventral stylomere, right half, ventral view; $\mathrm{C}$, gonocoxite and gonostyli, lateral view; $\mathrm{D}$, aedeagus, paramere and gonocoxal apodeme, left half, dorsal view. Scale 0.1 $\mathrm{mm}$.

situated at basal quarter of Sc; narrowest distance between $\mathrm{R}_{1}$ and $\mathrm{R}_{5}$ : distance between apices of $R_{1}$ and $R_{5}$ as $3: 10$; forking point of $\mathrm{CuA}$ slightly before level of subcostal apex. Fore tibia with spur shorter than others on mid and hind tibiae; mid and hind tibiae each with inner spur slightly shorter than the outer; fore tibia with $3-4 \mathrm{~d}, 2-4 \mathrm{pd}$; mid tibia with 7-9 ad, 4-9 d, 4-8 pd; hind tibia with 8-12 ad, 12-18 d, 2-6 pd; fore metatarsus about 1.6 times as long as tibia.

Eighth tergite (T8) with mediocaudal projection sclerotized as well as basal part, the projection almost as long as basal length of tergite(see Fig. $2 \mathrm{G}$ ), with long setae along posterior margin; T9 almost trapezoid, straight along posterior margin but shallowly emarginated at base (Fig. $1 \mathrm{~A}$ ). Gonocoxites entirely united to each other on ventral side, with narrow incision at middle and a hole inside of short posterolateral projection (Figs. $1 \mathrm{~B}, \mathrm{C}$ ); gonostylus with dorsal stylomere projected mesally, ventral stylomere with three short spines on tip, mesal stylomere membranous and semicircular (Figs. $1 \mathrm{~A}$, C); gonocoxal apodeme with spinulose membranous projection (Fig. 1 D); aedeagus with long basal apodeme (Fig. 1 D); parameres incurved on apices (Fig. 1 D).

Body length 5.2 (4.8-5.6, holotype) mm, wing length 4.3 (4.0-4.7, holotype) mm. 


\section{Female.}

Similar to male, but thorax slightly darker than in male; T3-5 more or less yellowish on lateral sides; wing length 4.5-4.6 mm, forking point of $\mathrm{CuA}$ distinctly before subcostal apex; mid and hind femora slightly infuscated near apices; body length 5.2$5.3 \mathrm{~mm}$.

Type material. Holotype male (OMNH TI 180), Mt. Ôdaigahara, Nara Pref., 1. VIII. 1972, T. Kimura. Paratypes: $2 \sigma^{\top} 2$ 우, same data as in holotype; $5 \sigma^{\top}$, Koza, Wakayama Pref., 28-29. IV. 1962, M. Sasakawa; $3 \sigma^{7}$, Kii-Ôshima, Wakayama Pref., 30. IV. 1962, M. Sasakawa; $10^{\nearrow}$, Kami-Ichikawa, Echigo, 27. VI. 1954, H. Koike.

Distribution. Japan (Honshû).

Remarks. This testaceous species shows similarity to European Neuratelia minor (Lundström, 1912) in the shape of T9 and in the presence of dorsal and ventral stylomeres of gonostylus (Matile, 1974, Fig. 6). However, there are some differences between them in the size, structure of ventral stylomere, and shape of paramere. Also, the spinose ventral stylomere of their species is similar to that of Neuratelia nigricornis Edwards, 1941(Matile, 1974, Figs. 3,5), but nigricornis has more dense spinulae on the stylomere and two strong spines on the posterodorsal apex of gonocoxite.

Variation. Second and third flagellomeres sometimes entirely yellow; mediotergite and laterotergite sometimes tinged faintly with brown; T2 and T3 rarely dark testaceous; T2-5 rarely yellowish along posterior lateral margins.

\section{Neuratelia yukawai sp. nov.}

(Fig. 2)

Diagnosis. This is distinctive in having a stout denticulation on gonostylus, which is not divided into the dorsal and ventral stylomeres, and about six strong setae on its dorsoproximal lobe, and about ten stout but short setae on tip of ventrodistal projection of gonocoxite.

Male.

Head dark brown but face and clypeus testaceous; antenna pale brown but scape, pedicel and first flagellomere yellow, second flagellomere more or less yellowish at base; palpus yellow. Mesoscutum and scutellum testaceous, weakly shining, lateral side of scutum and pleura testaceous yellow. Wing hyaline, very faintly yellowishtinged; halter yellow, knob brown-tinged. Legs yellow, tarsi slightly tinged with brown. Abdomen with tergites shiny, dark brown and sternites yellow; gonocoxite pale brown, gonostylus with black conical denticulation near base.

External structures are similar to those of $N$. japonica n. sp., but there are some differences between two species as follows: in yukawai, median small ocellus is situated 


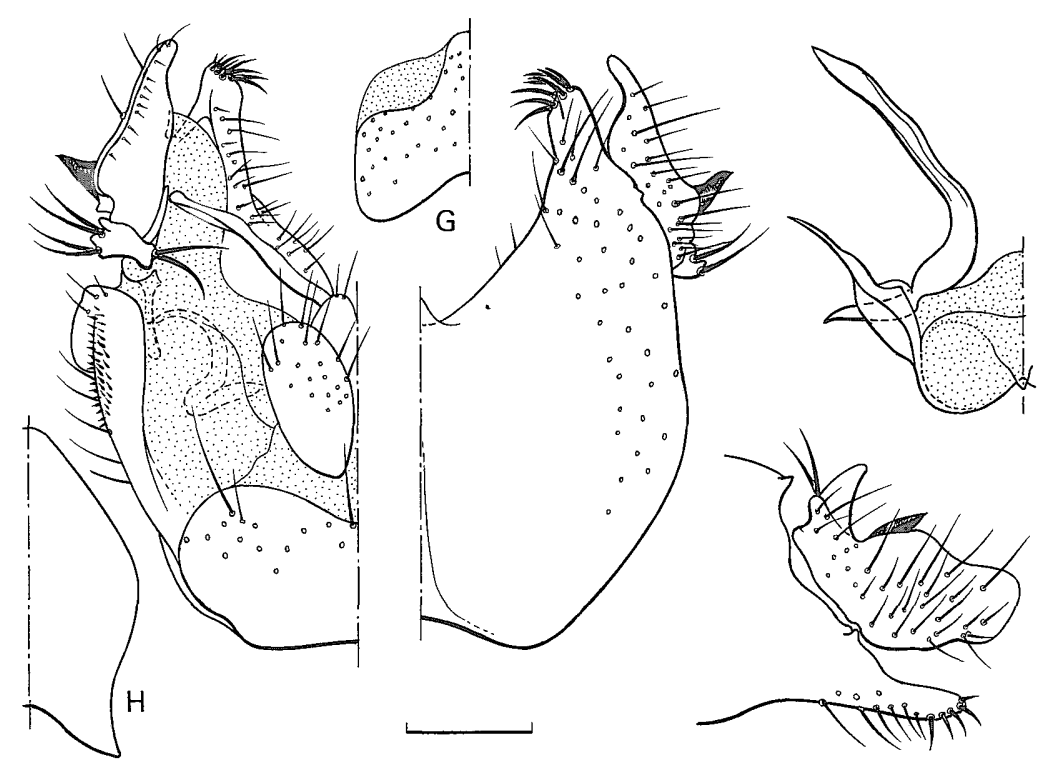

Fig. 2. Male genitalia of Neuratelia yukawai sp. nov. (holotype). G, right half of eighth tergite; $\mathrm{H}$, right half of eighth sternite. See Fig. 1.

just before the line of lateral ocelli; basal flagellomeres are in relative length of 3.6 (first) : 2.6(second to fifth), fourth flagellomere almost twice as long as wide; scutellum is provided with six marginal setae (distinguishable by pits); subcosta is terminated slightly before middle of distance between $h$ and apex of $R_{1}$, crossvein sc-r is situated at basal one-third of $S c$, narrowest distance between $R_{1}$ and $R_{5}$ : distance between apices of $\mathrm{R}_{1}$ and $\mathrm{R}_{5}$ is as $3.3: 10$; inner spurs of mid and hind tibiae are distinctly shorter than the outers.

Ninth tergite with emargination on posterior margin; T8 similar to that of japonica in shape (Fig. 2 G); S8 almost pentangular, nearly twice as long as T8 (Fig. $2 \mathrm{H}$ ). Gonocoxite minutely spinulose on posterior lateral area, and with ten to twelve dark brown long or short spine-like setae on tip of ventrodistal projection; gonostylus with about six dark brown strong setae on dorsoproximal lobe and one very strong tooth projected posterodorsally; parameres well-extended laterally.

Body lengh $4.3 \mathrm{~mm}$, wing length $3.5 \mathrm{~mm}$.

Femalle. Unknown.

Type material. Holotype male (HU), Is. Amami-Ôshima, V. 1959, K. Kamijo; distal flagellomeres of antenna, fore and left mid legs missing; abdomen and genitalia in a tubule and pinned with the specimen.

Distribution. Japan (Kyushû).

Etymology. It is my pleasure in dedicating this new species to Prof. Junichi Yukawa, 
who had contributed to the progress of our Cecidology.

\section{Neuratelia tibialis sp. mov.}

(Fig. 3)

Diagnosis. This testaceous species is unique in having the basally dilated mid tibia and posteriorly furcate ninth abdominal tergite, and in the peculiar structures of gonostylus and paramere of male genitalia.

Male.

Testaceous; head with brown band below lateral ocelli; antenna brown, scape, pedicel and first flagellomere yellow, neck part of flagellomere pale yellowish brown; palpus yellow; mesoscutum paler than scutellum, shiny; abdominal tergites shiny brown, T24(5) each with yellowish posterolateral parts; genitalia pale brown. Wing hyaline, very faintly smoky; halter yellow. Legs yellow, distal margins of all femora narrowly brown, tarsi slightly brown-tinged.

This species is distinguishable from $N$. japonica $\mathrm{n}$. sp. by the following characters: median ocellus on a transverse central line between lateral ocelli; antenna extending slightly beyond posterior margin of scutellum, flagellomeres in relative length of 5.5(first) : 3.5(second) : 3-3.2(third to thirteenth) : 4(fourteenth), fourth flagellomere about 3.3 times as long as wide; palpomores in relative length of $2: 2.5: 2.7: 5$; scutellum with a pair of long apical setae; forking point of $\mathrm{CuA}$ distinctly before subcostal tip; narrowest distance between $R_{1}$ and $R_{5}$ : distance between apices of $R_{1}$ and $\mathrm{R}_{5}$ as 3.5-4 : 10; mid tibia swollen on basal half, in broadest part nearly 1.7 times as wide as distal thickness; fore tibia with 3 ad, 2 d, 3-4 pd; mid tibia with 6-11 ad, 4-5 d, 9-14 pd; hind tibia with 12-20 ad, 15-26 d, 6-9 pd.

Ninth tergite narrowed distally, forming a pair of sharp projections on posterior margin by a deep emargination; T8 almost trapezoid, less than one-half as long as T9 (Fig. 3 G); S8 pentangular, slightly longer than S7, nearly 3.5 times as long as T8 (Fig. $3 \mathrm{H}$ ); cercus narrow. Gonocoxite of normal shape; dorsal stylomere of gonostylus with clavate process mesally, ventral stylomere with two teeth at middle of both dorsal and ventral margins (Fig. $3 \mathrm{E}$ ); paramere with dorsal process slender and sinuate, and ventral process hooked apically (Fig. 3 D).

Other external characters are as in japonica.

Body length 4.3 (holotype) mm, wing length 4.0 (holotype) $-5.0 \mathrm{~mm}$.

Femalle. Unknown.

Type material. Holotype male (OMNH TI 181), Koza, Wakayama Pref., 28-29. IV. 1962, M. Sasakawa; genitalia in a tubule and pinned with the specimen. Paratype: ऽ?, Kamishiiba, Fukuoka, 8. VI. 1955, M. Takahashi. 


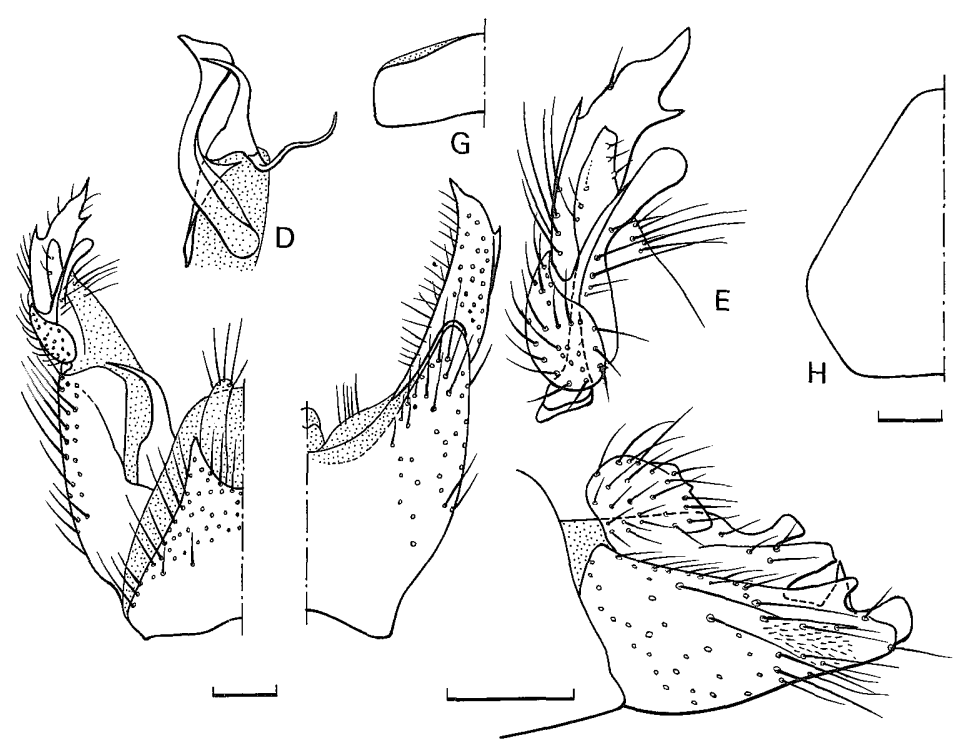

Fig. 3. Male genitalia of Neuratelia tibialis sp. nov. (holotype). D, paramere and gonocoxal apodeme; E, gonostylus, inner view. See Figs. 1-2.

Distribution. Japan (Honshû, Kyushû).

Remarks. This species is similar to N. femorata Okada, nemoralis (Meigen) and kamijoi n. sp. in having two processes of paramere beside aedeagus, but its shape and apical direction of ventral process are distinctive as described above.

Etymology. The specific name refers to the dilated mid tibia.

\section{Neuratelia femorata Okada}

Neurotelia femorata Okada, 1937, Mushi 9: 73.

This blackish species is characterized by having about twenty pale brown, long bristles arranged in two rows on ventral side of yellowish fore femur; wing length 4.5$6.2 \mathrm{~mm}$. The gonostylus is slightly thickened at middle and pointed apically when viewed from above but truncated on apex in lateral view, and is provided with a minute process at ventromesal base; paramere consists of apically boot-shaped and claw-like processes.

Distribution. Japan (Hokkaidô, Honshû, Kyushû). 


\section{Neuratelia microdigitata sp. nov.}

(Fig. 4)

Diagnosis. This dark species is easily recognized by the pale brown fourth segment of palpus and bicolored abdomen. The male genitalia are highly specific in the structures of dorsal, mesal and ventral stylomeres of gonostylus.

Malle.

Head black, face and clypeus slightly brown-tinged; antenna with scape testaceous, pedicel and first flagellomere yellow, second flagellomere yellow to brownish yellow, third (-fourth) flagellomere brownish yellow at base, other flagellomeres pale brown; palpus yellow but fourth palpomere pale brown. Thorax shiny brownish black, pleura and mediotergite slightly paler than scutum. Wing hyaline, very faintly tinged with brownish yellow; halter yellow. Legs yellow, tarsi faintly brown-tinged. Abdomen shiny brown, T2-5 and S2-6 with yellow posterior margins, yellow markings on tergites each broadened laterally into a triangle. Setae and setulae are pale yellowish brown.

External structures are similar to those of $N$. japonica $n$. sp. except for the following points: median ocellus situated just before anterior line of lateral ocelli; face and clypeus more densely setigerous; antennal flagellomeres in relative length of 4.7-5 (first) : 3 (second) : 2.8 (third to fourth) : 3-3.5 (fifth to thirteenth) : 4.6 (fourteenth), fourth flagellomere about 1.6 times as long as wide; palpus with four palpomeres in
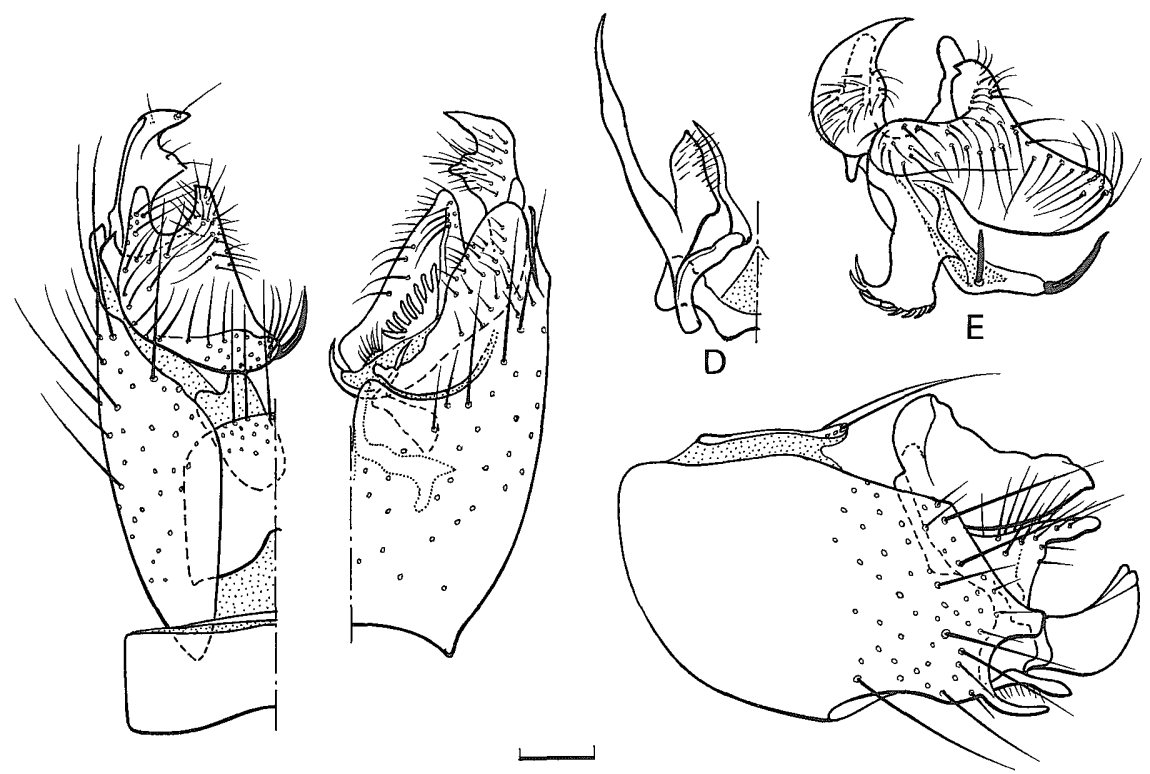

Fig. 4. Male genitalia of Neuratelia microdigitata sp. nov. (paratype, Nara). See Fig. 3. 
relative length of $1.7: 2.6: 4.5: 8$, first palpomere setose only on apex, second setose on lateral side, and third to fourth setose throughout whole length; scutellum with 2-3 pairs of apicomarginal setae long; costa extending a little beyond tip of $R_{5}$, subcosta ending in costa at basal two-fifths of distance between $h$ and tip of $R_{1}$, sc-r usually at basal one-third of $S c$, narrowest distance between $R_{1}$ and $R_{5}$ : distance between apices of $R_{1}$ and $R_{5}$ as $3: 10$, forking point of CuA slightly before apex of $S c$; fore tibia with $2 d$, 2-5 pd; mid tibia with 5-6 ad, 4 d, 5-6 pd; hind tibia with 5-9 ad, 7-9 d, 8-9 pd; fore metatarsus almost as long as tibia $(1.1: 1)$.

Ninth tergite with a shallow cleft anteriorly, T8 with anterior margin shallowly emarginated. Gonocoxite with claw-like process below hole on each posteroventral margin; gonostylus with dorsal and ventral stylomeres each bifurcated distally, mesal stylomere large, composed of 8-9 short finger-like processes, a process with two strong spines directed inward and setose lobes; paramere short, gonocoxal apodeme with a small setose lobe.

Body length 4.8 (4.5 in holotype -5.5$) \mathrm{mm}$, wing length 4.2 (4.0 in holotype, 3.8-4.6) mm.

\section{Female.}

Similar to male, but paler than male: head dark brown, clypeus pale brown, thorax and abdominal tergites brown, T2-6 and S2-7 with posterior margins distinctly yellow (narrow in T6 and S7); body length 4.6 (4.4-4.7) mm, wing length 4.5 (4.4-4.6) mm.

Type material. Holotype male (OMNH TI 182), Kibune, Kyôto, 27. V. 1953, M. Sasakawa. Paratypes: 1 그, Kasuga, Nara, 26. IV. 1955, M. Sasakawa; 1 구7우, Nikawa-cho, Kure, 30. IV. 1955, Z. Sawano; $1 \sigma^{7}$, Ishiyama, Ôtsu, 19. IV. 1973, T. Kimura; 1 ऽ, Ooe, Kyôto, 11. V. 1973, T. Kimura.

Distribution. Japan (Honshû).

Remarks. The gonostylus, especially complicated mesal stylomere, of this species is highly specialized, differing from all the known Palaearctic species.

Etymology. The specific name refers to the minute finger-like processes on mesal stylomere.

\section{Neuratelia nemoralis (Meigen)}

Mycetophila nemoralis Meigen, 1818, Syst. Beschr. europ. zweifl. Insekt. 1: 265.

This is a large (5-6 $\mathrm{mm}$ in wing length) and dark (head and thorax brownish black, abdomen dark brown) species. Its characteristic pregenital tergites in male and genitalia are similar to those of $N$. kamijoi $\mathrm{n}$. sp., that is, T8 and T9 each excavated at middle of anterior margin (the excavation about one-half as long as whole length of 
tergite), gonocoxite distinctly projected at dorsal and ventrolateral ends (in this species the dorsal process gradually narrowed distally, not pointed on tip, and not dentate as in kamijoi ), and paramere with long claw-like, incurved apical part.

Antennal flagellomeres pale brown, but first flagellomere yellow in both sexes, second flagellomere in male and second to fourth flagellomeres in female testaceous yellow; narrowest distance between $R_{1}$ and $R_{5}$ : distance between apices of $R_{1}$ and $R_{5}$ as 3 : 10 ; fore metatarsus slightly longer than tibia (3.5:3); fore tibia with $2 \mathrm{ad}, 1 \mathrm{~d}, 3 \mathrm{pd}$; mid tibia with 4-5 ad, 7-9 d, 3-5 pd; hind tibia with 10-12 ad, 10-12 d, 6 pd.

Distribution. Japan (Hokkaidô, Honshû); Holarctic.

\section{Neuratelia kamijoi sp. nov.}

(Fig. 5)

Diagnosis. This blackish species is unique in having two teeth before apex in addition to pointed tip of dorsal prolongation of gonocoxite.

Male.

Head and thorax black but clypeus and thoracic pleura brownish black; vertex densely and mesoscutum sparsely grayish pollinose; mesoscutum weakly shining laterally. Antenna pale brown, but first flagellomere yellow basally and testaceous distally; palpus yellow but first palpomere testaceous and fourth palpomere brown-tinged on
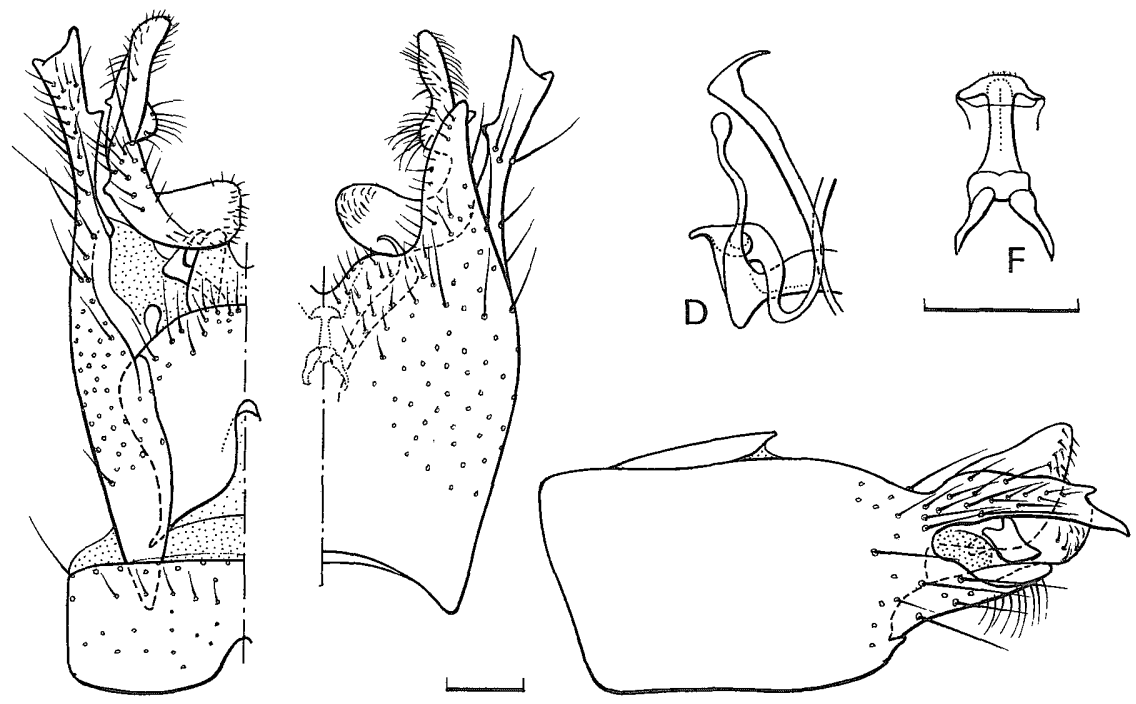

Fig. 5. Male genitalia of Neuratelia kamijoi sp. nov. (holotype). F, aedeagus. 
apical one-fifth. Wing hyaline, very faintly yellowish tinged; halter yellow. Legs yellow, tarsi slightly brown-tinged. Abdomen shiny, blackish brown, but sternites brown.

External structures are similar to those of $N$. japonica $n$. sp. except for the following points: antennal flagellomeres in relative length of 5.5 (first) $: 3.8$ (second) $: 3.7$ (third to fourth) : 3.4 (fifth to sixth) : 3.6-3.7(seventh to ninth) : 3.5(tenth to thirteenth) : 4.2(fourteenth); palpomeres in relative length of $1.6: 2: 3.4: 5$; costa slightly extending beyond tip of $R_{5}$, Sc ending slightly before middle of distance between $h$ and $R_{1}$, forking point of $\mathrm{CuA}$ distinctly before apex of Sc; fore metatarsus slightly shorter than tibia (2.7-2.8 : 3); fore tibia with 1-2 ad, 3-4 pd; mid tibia with 6-7 ad, 1-2 d, 4-5 pd; hind tibia with $8-10$ ad, $8-10 \mathrm{~d}, 3-5 \mathrm{pd}$.

Pregenital tergites and genitalia of this species are characterized as follows: T9 with a distinct median cleft (nearly two-thirds as long as whole length of tergite) on anterior margin, T7 and T8 each with median cleft shallow; gonocoxite with distinct dorsal and ventrolateral projections, the former dentate before apex; dorsal stylomere of gonostylus simple, with basal lobe directed inward; aedeagus pale brown (Fig. 5 F); paramere consists of two processes, of which inner process with sickle-shaped apex and outer one with knob-like apex (Fig. 5 D).

Body length $5.5 \mathrm{~mm}$, wing length $4.8 \mathrm{~mm}$.

Female. Unknown.

Type material. Holotype male (HU), Sapporo, 1. VI. 1960, K. Kamijo ; tubule containing terminalia pinned with the specimen. Paratype: $1 \sigma^{\top}$, same data as holotype.

Distribution. Japan (Hokkaidô).

Etymology. The species is named after the collector, Dr. Kazuaki Kamijo, Hokkaidô, who also collected the specimen of $N$. yukawai described as new to science in this paper.

\section{Acknowledgments}

I wish to extend my thanks to Dr. S. Takagi (Hokkaidô University) and Mr. T. Kimura (Higashiyama High School, Kyoto) for allowing me to study the specimens in their care.

\section{References}

Kimura, T., 1976. Notes on some fungus-gnats from Japan (I) (Diptera, Mycetophilidae). Higashiyama-Gakuen Kenkyu-Kiyô, (21): 15-25. (In Japanese.)

Landrock, K., 1927. Fungivoridae (Mycetophilidae). In Lindner, E.(ed.): Die Fliegen 
der palaearktischen Region, 8: 1-195. E. Schweizerbart'sche Verlagsbuch, Stuttgart.

Matile, L., 1974. Notes sur les Mycetophilidae (Diptera) de la Faune de France. III. Le genre Neuratelia. L'Entomologiste, 30: 26-33.

Matile, L., 1988. Tribe Sciophilini, Sciophilinae, Mycetophilidae. pp. 231-241, In Soós, A. \& L. Papp, (eds.), Catalogue of Palaearctic Diptera, Vol. 3, CeratopogonidaeMycetophilidae. Elsevier, Amsterdam.

Okada, I., 1937. Einige Fungivoriden aus Kiushiu (Dipt., Fungivoridae). Mushi, 9: 7380. (In Japanese.)

Okada, I., 1939. Studien über die Pilzmücken (Fungivoridae) aus Hokkaido (Diptera, Nematocera). J. Fac. Agr., Hokkaido Imp. Univ., 42: 267-336.

Sasakawa, M., 1965. Diptera: Mycetophilidae. p. 187, In: Iconographia Insectorum Japonicorum (Colore naturali edita) III. Hokuryukan, Tokyô. (In Japanese.) 


\section{.}

